UDK 81’373.46

Pregledni rad

Rukopis primljen 23. IX. 2019.

Prihvaćen za tisak 23. I. 2020. doi.org/10.31724/rihjj.46.2.5

\title{
Владимир Дубичинский
}

Варшавский университет

Ул. Штурмова 4, PL-02-678 Варшава

v.dubichynskyi@uw.edu.pl

\section{НЕКОТОРЫЕ СОВРЕМЕННЫЕ ВОПРОСЫ ТЕРМИНОГРАФИИ}

В статье раскрывается основной спектр вопросов, которые в настоящее время решает терминография - синтетическая наука о теории и практике создания терминологических словарей. Освещаются: наиболее важные проблемы современной теориитерминографии; основныевидыиэтапысозданиятерминологическихсловарей; требования к ним; алфавитный, алфавитно-гнездовой и идеографический принципы составления словарей; стандартизация терминологии как вид терминографической деятельности; учебная терминография; компьютеризация терминографии и др.

I. Энциклопедический словарь “Общее терминоведение” 2006 года определяет терминографию как «отрасль терминоведения, занимающаяся теорией и практикой составления терминологических словарей. Терминография называется также научно-технической лексикографией и терминологической лексикографией» (Tatarinov 2006: 239). Отдавая дань справедливости такого определения, хочется заметить, что сегодня эта отрасль поправу является не только отраслью терминоведения, но и одним из направлений науки, техники и производства в целом, т.к. в словарной форме исследует терминологический аппарат и предлагает понятийное видение каждой отрасли промышленности, сельского хозяйства, культуры.

Терминография представляет собой науку о теории и практике создания терминологических словарей. Эта дисциплина мне представляется комплексной, объединяющей терминоведение как науку о терминах и лексикографию как искусство создания словарей. 
С самого начала следует принципиально отметить диалектическое двуединство терминографии как науки. Являясь, с одной стороны, отдельной научной дисциплиной в ряду других дисциплин, терминография, с другой стороны, представляет собой универсальную методологическую науку, необходимую самым разным областям человеческой практики.

Без терминологических словарей невозможны научные исследования в математике, биологии, информатике, культурологии и т.п., словари признаются основными, программными источниками многих научных дисциплин. Именно поэтому современными отечественными и зарубежными лингвистами терминография в настоящее время считается синтетической наукой.

Терминографию как синтез можно рассматривать также и в том смысле, что она вбирает в себя воедино как теоретические исследования, так и практические, прикладные аспекты научных изысканий в различных областях человеческой деятельности.

Совершенно ненужным мне представляется виртуальный “спор” ведущих современных терминологов, в котором высказаны два якобы “противоположных" мнения: постулат о лингвистической основе терминоведения как научной дисциплины, принятый Российским терминологическим обществом РоссТерм (Tatarinov 2006: 161) и возражения авторского коллектива под руководством А.В.Суперанской: “Специальная лексика не может изучаться на тех же основаниях, что и лексика общая, поскольку она системна и тематически организована иначе” (Superanskaja 2005: 11).

Основным объектом изучения терминографии является термин во всех его особенностях и взаимоотношениях. Однако термин изучается с различных позиций и другими техническими, естественными и гуманитарными науками. В этом отношении следует подчеркнуть посредническую роль терминографии между лингвистикой, которая занимается языковыми свойствами терминов, и другими науками, которые сосредоточиваются на изучении его понятийных сторон.

Следует лишь учесть, что, если каждая научная дисциплина описывает соответствующую терминосистему на уровне logos’a, то терминография выполняет эту функцию с позиций lexis’a. Благодаря синтезирующему, 
всеохватывающему характеру лингвистических исследований, воплощаемых в терминологических словарях, терминография интегрирует всеобщее научное знание и мировоззренческие позиции.

Посредническая роль терминографии ощущается также и с лингвистической точки зрения: от теоретической лингвистики она получает основные понятия и принципы, а прикладному языкознанию для решения практических задач даёт необходимую систематизацию знаний и терминологических единиц.

Следует различать: фиксирующую терминографию, задачей которой является описание, классификация, разработка терминов и их точных, кратких и простых истолкований; предписывающую терминографию, задачей которой является указание, какой термин следует использовать в той или иной ситуации письменного и устного научного общения (терминологические стандарты, словари рекомендуемых терминов).

В своё время С.И.Ожегов подчеркнул: “С одной стороны, должны готовиться терминологические словари “собирательного” типа для выявления богатств национальной, самобытно создававшейся профессиональной терминологии... С другой стороны, следует поставить вопрос о создании терминологических словарей “кодификационного” типа” (Ožegov 1974: 244).

II. В связи с этим подчеркну, что терминография представляет собой один из важнейших видов человеческой деятельности в области терминологии, задачами которого являются систематизация, упорядочение и унификация научной терминологии. Терминография призвана выполнять три основных функции: а) систематизирующую; б) справочную; в) учебную.

Учитывая терминографический бум двух последних десятилетий, следует отметить, что на наших глазах удваивают и утраивают свои логико-понятийные мощности традиционные науки, зарождаются и формируются ресурсы новых наук.

Как отмечает С.В.Гринёв, рост числа терминов различных наук обгоняет рост числа общеупотребительных слов языка и поэтому в настоящее время число терминов отдельных наук (биологии, химии) может превышать число неспециальных слов языка на несколько порядков. Достаточно привести следующие цифры: в биологии число названий насекомых превышает 
1,5 млн., а общее число известных видов организмов может достигать 100 млн. специальных наименований (Grinëv 2018: 177-178).

Основными проблемами современной теории терминографии являются сегодня, прежде всего:

- разработка методологических принципов создания терминологических словарей;

- создание научно обоснованной типологии специальных словарей;

- разработка инвариантного проекта словаря для описания различных специальных пластов лексики;

- определение основных параметров терминологических словарей;

- выработка принципиальных требований к терминографическим произведениям;

- исследование макро- и микроструктуры словаря;

- анализ путей отбора терминологического словника;

- выработка основных приёмов и методов описания терминов;

- применение компьютеризации в создании терминологических словарей;

- создание терминологических баз данных и автоматизированных рабочих мест терминолога и др.

Исходя из стратификационной модели лексики функционально связанных текстов обычно выделяют пять различающихся по функциональной связанности пластов: а) общеупотребительную лексику; б) общеспециальную нетерминологическую лексику; в) общеспециальную терминологию; г) общеотраслевую терминологию; д) терминологию частных областей (Morkovkin 1988: 181).

В связи с этим, учитывая принадлежность терминологической лексики лишь к трём из выделенных В.В.Морковкиным пластов, выделю три вида качественно отличающихся терминологических словарей:

1) общенаучные и общетехнические;

2) отраслевые терминологические словари;

3) узкоспециальные словари. 
III. Объективно развитие терминоведения опережает достижения терминографии. Отчасти такое опережение объясняется тем, что терминологические словари составляют, как правило, специалисты узких отраслей знаний, не имеющие достаточной языковедческой подготовки. Задача терминографии поэтому и состоит в объединении усилий специалистов и лингвистов на поприще терминологического «словаростроения». Призвание создателей терминологических словарей состоит в этой связи в том, чтобы как можно быстрее уменьшить этот разрыв, выдвинув научно обоснованные принципы практической работы над терминологическими словарями.

Наиболее общие требования к терминологическим словарям сформулировал C.В.Гринёв (Grinëv 2009: 61): адекватный охват специальной лексики избранной предметной области; наличие необходимой информации о специальных лексических единицах; отсутствие ненужных сведений, увеличивающих объём словаря и затрудняющих поиск нужной информации; унификация композиции и ссылочного аппарата однотипных словарей для облегчения пользователям перехода от одного словаря к другому; максимальная гармония между всеми элементами методической установки и композиции словаря.

Основные этапы подготовки терминологических словарей наиболее точно и сжато описаны B.M.Лейчиком (Lejčik 1975: 12): 1) просмотр литературы; 2) составление картотеки предполагаемых терминов; 3) отбор терминов и их редактирование специалистами; 4)составление схемы понятий; 5) составление алфавитной картотеки; 6) подбор эквивалентов.

А.С.Герд предлагает (Gerd 1986: 25) выделить хронологические рамки терминологического словаря. Вопрос этот, к сожалению, применительно к терминологическим словарям никогда не ставился, а между тем ни язык художественной литературы, ни устная разговорная речь не меняются столь быстро, как язык науки и техники.

IV. Состав терминологического словаря мне представляется следующим:

1. однословные термины (морфема, рекогносцировка, нейтрино и т.п.);

2. терминологические словосочетания: а) словосочетания-термины 
(когнитивное терминоведение, картофелеуборочный комбайн, акционерное общество и т.п.); б) свободные (обычно предсказуемые) терминологические словосочетания (стратегическая инициатива, биологический закон, коэффициент полезного действия т.п.);

3. термины-аббревиатуры (CTO, юрфак, МИД и т.п.);

4. номенклатура - названия конкретных объектов данной отрасли знания (автомобиль «Мерседес», стиральная машина “Горение”, электрофреза ФС-0,7 и т.п.); вопрос о включении номенклатурных наименований в терминологический словарь открыт; решение его задача авторов в каждом конкретным случае.

Отбор терминологического словника предлагаю ориентировать на следующие необходимые требования, которые довольно подробно описаны в терминоведческой литературе: систематичность термина, краткость, ясность, простота, обладание словообразовательными возможностями, эвфония (благозвучность), соответствие лингвистическим правилам и нормам языка. Отбор терминов для словаря производится в значительной степени под влиянием методологической концепции автора.

Одним из важнейших условий формирования словника терминологического словаря является предварительное моделирование логико-понятийной системы, характерной для описываемой в словаре отрасли знаний.

V. Из множества проблем терминографии кардинальной является проблема определения (в широком логико-философском понимании), проблема семантизации единиц словаря. Любое идеальное научное понятие только тогда становится достоянием научной мысли, становится доступным для исследования, когда оно выражено словесно с помощью термина и введено в научную теорию с помощью определения.

Первый (и основной) методологический постулат терминографической семантизации - адекватная семантизация производна от целого пучка образующих «сил»: типа и размера словаря, потребителей словаря, от простоты/сложности семантической структуры семантизируемых единиц, точности отбора вокабул словаря, уровня методологии и методики терминологической теории, терминографической традиции и даже - профессионального уровня. 
Второй методологический постулат - примат терминографической прагматики и определённого компромисса между терминографической теорией и терминографической практикой, с одной стороны, и степенью «снятия» терминографических антиномий, с другой стороны, позволяют обсудить границы применения тех или иных приёмов описания и соотношения между различными терминографическими параметрами: 1) критерии отбора вокабул словаря; 2) вопрос об использовании иллюстративного материала; 3) обоснование системы помет; 4) совершенствование основных средств семантизации; 5) построение словарной статьи (Komarova 1995 : 43-44).

Описание термина в толковом терминологическом словаре предлагается разделить на две части. Первая часть - системное определение термина, которое можно представить в виде тезаурусного описания с семантически интерпретированными связями. Вторая часть - толкование, освобождённое от требования системности, свободное по форме, краткое и доступное.

VI. Хорошо известен и заслуженно оправдал себя алфавитный принцип как наиболее удобный способ размещения и поиска слов в словаре.

Многие терминологические словари составляются также по алфавитногнездовому принципу: неоднословные термины или терминологические словосочетания помещаются в словаре не только по алфавиту первого слова, но и при опорном термине-существительном (терминологическом ядре) и оказываются собранными как бы в одном гнезде.

Считаю данный принцип одним из продуктивных в терминографической практике и необходимых с точки зрения преподавания языка. Для примеpa см. словари Харьковского лексикографического общества (Dubičinskij, Valit i dr. 1990; Dubičinskij, Klebanova 1993; Dubičinskij, Romanov i dr. 1996; Drozd, Dubičins' kij ta inši 1997; Dubičinskij, Zubareva i dr. 2000; Evdoŝenko, Dubičinskij i dr. 2006; Dubičinskij, Laudin i dr. 2015).

В то же время многочисленные практические потребности специалистов свидетельствуют о том, что терминологический словарь может быть построен по идеографическому принципу, на логико-понятийной основе, на базе научной классификации понятий, что соответствует логике развития 
данной науки, отрасли знания и даёт возможность удобнее найти термин по его значению и месту в терминосистеме.

Идеографическое описание - это анализ системы специальных понятий. Исходя из системности как неотъемлемого свойства термина, идеографический словарь основывается на логико-понятийном анализе терминосистемы.

VII. Идеальный и, пожалуй, наиболее удобный способ однозначного соотношения означаемого и означающего - когда каждому термину соответствует всегда только один концепт и наоборот. Добиться такого лексикографического решения в реальных условиях живого языка практически невозможно. Однако теоретически в области терминологии такая задача абстрактно выполнима. Средством осуществления её может служить стандартизация, а терминографическим воплощением - стандарты на термины.

Стандартом на термины и определения называют словарь системного типа, имеющий официальный, государственно-правовой характер. Большинство требований терминологических стандартов является обязательным для применения в различных видах документов. Существуют и рекомендуемые требования. К началу 90-х годов в мире действовало более 20 тысяч стандартов на термины и определения. Основная их часть - это национальные стандарты, которые разрабатываются во всех промышленно развитых странах. Кроме того, существуют международные стандарты (их более двухсот), региональные стандарты, стандарты фирм и международных организаций (Lejčik 1996: 207-208). В последнее десятилетие активно разрабатываются сотни стандартов на термины украинского языка.

Не следует отождествлять терминологические стандарты (ТС) со словарями рекомендуемых терминов (СРТ). Они отличаются, как правило, способом подачи материала и уровнем нормативности. У СРТ уровень нормативности минимальный, у ТС - максимальный. Именно максимальная нормативность обеспечивает терминологическому стандарту свойство арбитражности - способности быть юридическим документом.

Термин«арбитражностьтерминологическогостандарта»ввёлК.Я.Авербух, который под арбитражностью ТС как юридического документа понимает 
его “свойство быть достаточным основанием для решения Суда или органами Государственного арбитража вопроса о соотнесении того или иного термина (словесного наименования) с определённым материальным объектом или понятием профессиональной сферы деятельности, в том случае, если спорящие (конфликтующие) стороны разошлись в вопросе о единицах называния данной предметной области" (Averboukh 2006: 206).

Однако, по моему мнению, к стандартизации терминологии следует относиться с определённой долей условности. Необходимо отдавать себе отчёт в том, что строгая, жесткая стандартизация - это в конечном счёте формализация научного мышления. Ведь каждый научный труд (будь то монография, методическая разработка, словарь) - авторское произведение, в котором не последнюю роль играют такие “враги” стандартизации, как синонимическое варьирование, право автора на введение в научную теорию нового термина и т.п.

Следует отметить также ещё один интересный аспект терминографических исследований - терминологические словари языка писателей. Например, последние десятилетия наблюдается расцвет шекспировской терминографии (см. Karpova 2009: 150-153).

VIII. Терминография обладает необходимым лингвометодическим зарядом. Учебные задачи терминологических словарей считаются основными в терминографии. Средства семантизации терминологической лексики в учебных терминологических словарях весьма разнообразны. Они выработаны общей лексикографией и терминографией, подсказаны методикой преподавания научного стиля языка. Создаются новые специфические средства описания терминов, что подтверждается всё возрастающим количеством разнообразных терминологических словарей. Одной из главных проблем учебной терминографии является разработка базового терминологического словаря.

Базовый терминологический словарь включает тематически представленные отраслевые термины - необходимый для учащихся запас терминов, который позволяет в общих чертах понимать тексты по специальности и служит базой для формирования более полного словарного запаса при дальнейшей профессиональной работе специалиста. Так как отрасле- 
вые термины сравнительно легко укладываются в систему, базовый терминологический словарь строится по системному принципу изложения материала в учебниках или справочниках по специальности.

Обучение научному стилю речи предполагает включение в программу словарных материалов с определённой профессиональной ориентацией. При обучении языку любой специальности необходимо в первую очередь соблюдение требований строгой стандартизации, унификации и минимизации терминологической лексики.

Поэтому немаловажной проблемой для учебной терминографии является также разработка терминологических минимумов - функционально связанных лексических минимумов, которые содержательно отражают определённый фрагмент словарного состава, связанный с тем или иным подъязыком.

На мой взгляд, критериями включения термина в терминологический минимум являются прежде всего:

1) частотность употребления данного термина в текстах по специальности;

2) ценность его для данной терминосистемы;

3) уместность термина в определённых контекстах данного подъязыка. Овладение терминологическим минимумом необходимо учащемуся в качестве постижения системных основ терминологии изучаемой специальности. Вслед за В.В.Морковкиным, мне хотелось бы подчеркнуть, что терминологический минимум в определённом смысле задаёт не только языковой (терминологический) материал обучения, но и содержание обучения с точки зрения полного (в минимальных пределах, конечно) набора речевых средств, необходимых для формирования потенциального словаря специалиста в анализируемой области знаний.

IX. На мой взгляд, для повышения эффективности науки, в широком смысле слова, и гармоничного ее развития необходимо создание соответствующего лексикографического обеспечения, которое бы оперативно, гибко и адекватно реагировало на изменения методологической парадигмы науки. 
Для решения этой сложной комплексной проблемы необходимо решить ряд частных задач, из которых выделим следующие:

1. Проблему создания системы мониторинга, обеспечивающую сведениями о необходимости лексикографической поддержки той или иной развивающейся науки, того или иного научного направления.

2. Проблему создания словарно-справочных средств (ССС) различных типов на основе интеллектуальных информационных технологий.

3. Проблему оценивания качества ССС и достоверности сведений, помещенных в словари, справочники и энциклопедии.

4. Проблему повышения эффективности использования ССС при управлении когнитивными и учебными процессами в средних и высших учебных заведениях.

Решение этих задач видится в дальнейшем развитии теоретических основ лексикографии, направленных не только на компьютеризацию процессов создания ССС, но и решения информационных задач управления этими процессами.

$\mathbf{X}$. В настоящее время методическая база терминографии пополняется такими несвойственными ранее ей методами исследования как моделирование, формализация и аксиоматизация языков, правил составления ССС, которые считаются традиционными для технических наук, в частности, кибернетики. Такое проникновение традиционных методов кибернетики в лексикографию является признаком того, что на рубеже веков зарождается новая комплексная наука - кибернетическая лексикография, объектом исследования которой, на наш взгляд, могут быть процессы информационно-лексикографического обеспечения познания, образования и науки в целом [см. подробнее Dubičinskij, Meteškin 2005].

Современная терминография сегодня уже невозможна без широкой компьютеризации. Постепенно традиционные методы заменяются компьютерной обработкой лексикографических данных. Компьютеризация терминографической деятельности заключается, прежде всего, в создании специализированных машинных терминологических банков данных и в разработке методов формирования этих банков, представления информации в банках и её использовании. Современная лексикография всё шире 
пользуется машинными банками данных, в частности, большими корпусами текстов на магнитных носителях, в которых компьютер по запросу осуществляет поиск нужных слов. На этой основе в последнее десятилетие сформировалось новое направление лингвистики - корпусная лингвистика и лексикография.

Под комплексной информатизацией научных исследований и прикладных разработок понимается:

1. последовательное оснащение современными компьютерами с перспективой их объединения в единую информационную сеть;

2. последовательное накопление на магнитных носителях и в базах данных главнейших источников, необходимых для научного изучения языка и осуществления прикладных разработок;

3. создание программных средств, необходимых для подготовки научных трудов, например, по языкознанию, и проведения прикладных разработок; развитие прикладных направлений (лексикографии, терминоведения, машинного перевода, автоматической обработки данных на естественном языке) как составной части академической и вузовской науки, являющихся, с одной стороны, проводником результатов фундаментальных исследований в практику, а с другой источником новых идей и данных для фундаментальной науки.

Научно-техническую лексикографию сегодня невозможно представить без автоматизированных терминографических систем, т.е. систем автоматизации подготовки и использования терминологических словарей, которые включают в себя программы, справочные данные, терминологические базы данных, необходимые для лексикографической обработки специальных текстов. В них используются текстовые редакторы для ввода и коррекции данных, программы контроля данных и запросов к системе, программы контроля орфографии и разметки входного текста, программы сегментации текста на слова, словосочетания, предложения и фрагменты словарных статей, программы лемматизации и подсчёта статистики словоупотреблений, программы загрузки, поиска, коррекции данных и др.

Введённые в систему тексты и/или терминографические произведения размещаются в базах данных и снабжаются словоуказателями и другими 
индексами, позволяющими по слову или его характеристикам находить его контексты или словарные статьи, в которых данное слово описано. Результатом автоматической обработки текста в автоматизированных лексикографических системах являются частотные словари, конкордансы (словоуказатели с контекстами), автоматические моно- и многоязычные словари, размещаемые в базах данных и используемые программами лексикографических систем в качестве справочного материала при обработке новых данных. Поэтому такие системы являются развивающимися системами. Электронные словари используются в системах автоматического перевода, а также в информационных системах и системах общения с компьютером на естественном языке в качестве справочников при подготовке и расширении словарей и уточнении грамматик этих систем.

В составе лингвистического обеспечения автоматизированных терминографических систем различают три группы функций автоматической обработки текста: автоматическое индексирование входных документов, составление поисковых предписаний по тексту запросов и автоматизированное ведение словарей системы. Ядром лингвистического обеспечения автоматизированных информационных систем являются информационно-поисковые тезаурусы, в терминах которых производится индексирование вводимых в систему текстов и запросов на их поиск. Индексирование текста заключается в составлении к нему поискового «образа», в котором указываются понятия, описываемые в тексте, и отношения между ними. Аналогично обрабатываются и запросы к системе. Сравнением поисковых предписаний с поисковыми образами документов осуществляется выбор текстов запрашиваемой тематики. Существуют и бестезаурусные системы, способные осуществлять поиск текстов по любым сочетаниям слов, встречающихся в них. В таких системах автоматически строятся словоуказатели к вводимым текстам.

“Появилась тенденция к синтезу всех видов нормализации терминов в нормативных словарях, куда включаются различные виды упорядоченных терминов - стандартизированные, рекомендуемые, избранные в качестве предпочтительных в информационных системах" (Grinëv 2018: 195).

XI. Обобщив и проанализировав современный опыт словарного дела, терминографы Харьковского лексикографического общества (Украина) 
пришли к выводу о создании так называемого автоматизированного рабочего места терминографа (АРМТ). АРМТ представляется мне универсальной терминологической базой данных или совокупностью терминологических баз данных, которыми терминограф может оперировать при создании электронных словарей.

На мой взгляд, разработка АРМТ - новый вид лексикографической деятельности, предполагающий творческое объединение усилий лингвистовтерминологов, лексикографов-практиков и программистов. В настоящее время термин «АРМТ» играет роль принципиального понятия компьютерной терминографии, так как на основе определенной универсальной совокупности терминологических баз данных предлагается стандартизировать и унифицировать весь лексикографический процесс, направить терминографическую деятельность в единое русло интернационализации электронно-словарных комплексов.

По идее современных терминографов АРМТ должно включать:

1) инвариантную электронную структуру словарной статьи, разработанную на основе баз данных толковых, терминологических, идеографических, переводных и др. словарей, которые также являются составными частями соответствующих баз данных;

2) в АРМТ необходимо наличие чётко разработанной системы условных знаков и лексикографических помет, которые должны быть снабжены соответствующим программным обеспечением;

3) компьютерную программу автоматического редактирования сканированных текстов и правки орфографических, грамматических, синтаксических и т.п. ошибок; и т.д.

Неотъемлемой частью автоматизированного рабочего места терминографа может стать автоматизированное рабочее место переводчика (АРМП), которое удовлетворяет всем лексикографическим и переводоведческим запросам лингвистов и помимо электронных словарных комплексов оснащается также современными системами машинного перевода - перевода текстов с одних естественных языков на другие с помощью программного обеспечения компьютера.

В рамках разработок систем машинного перевода следует упомянуть понятие “контекстологического словаря”, введённое Ю.Н.Марчуком 
(Marčuk 2007). Речь идёт о специальных словарях-конкордансах, которые учитывают терминологическую сочетаемость. "Каждый контекстологический словарь ориентирован на определённый корпус исходных текстов” (Marčuk 2018: 392). Таким образом, контекстологический словарь призван объединить конкордансное и корпусное описание терминов.

Языково-информационным фондом НАН Украины (Киев) в настоящее время ведётся работа над созданием виртуальной лексикографической лаборатории, которая сможет объединить в единое целое многие терминографические ресурсы.

В современной науке наблюдается тенденция к интеграции всех подходов к конструированию систем автоматической обработки текста в рамках конструирования искусственного интеллекта - направления в информатике, связанного с созданием сложных человеко-машинных и робототехнических систем, моделирующих человеческую деятельность в различных сферах и предметных областях. В таких системах текст на естественном или искусственном языке является как источником накопления знаний системы, так и источником данных для выбора её поведения, а также средством взаимодействия системы с человеком. Здесь функции редактирования всё больше сливаются с функциями содержательной обработки, образуя единый аппарат понимания текстов.

Компьютеризация открывает возможности для автоматизации наиболее сложных областей человеческой деятельности, требующих затрат прежде всего интеллектуального труда, таких, как редакционно-издательские процессы, извлечение информации из текстов, медицинская и техническая диагностика, экспертная деятельность, проектирование машин и сооружений, изготовление проектной документации, управление социально-экономическими системами и мн. др. Во всех этих случаях автоматическая обработка текста играет первостепенную роль.

Однако в таких массовых “промышленных” применениях автоматическая обработка текста должна опираться на мощную информационную поддержку в виде автоматизированных словарных картотек, электронных словарей, грамматик и других форм представления лингвистических данных в компьютере. Разработка таких систем приобретает форму машинных 
фондов национальных языков (например, Машинные фонды русского, украинского, чешского языков и т.д.), национальных автоматизированных лексикографических, в частности терминографических, служб и т. п.

XII. Как красноречиво доказывает весь ход научно-технического прогресса, компьютеризация словарной деятельности существенно расширяет возможности терминографов. Развитие компьютерных технологий подсказывает необходимость полной компьютеризации словарных исследований. И это подтверждают сейчас новые направления терминографии: создание словарных картотек на основе компьютерных баз данных, электронное построение словарных статей и автоматическая обработка терминологического материала, составление печатных словарей на компьютерной основе и создание собственно электронных словарей (без их бумажных аналогов) и мн. др.

И, мне кажется, именно развитие компьютерных словарных исследований, наряду с глубокими традиционными лингвистическими и переводоведческими открытиями, определяет широкое будущее терминографии.

Таким образом, на основе анализа места и роли современной лексикографии в методологии науки можно сформулировать проблемы, решение которых направлены на создание новой комплексной науки - терминографии. Объект исследования этой науки видится в моделировании различных аспектов человеческих знаний и представлении их в словарной форме.

\section{ЛИТЕРАТУРА}

Averboukh 2006. = Аверьух, КонстАнтин. 2006. Общая теория термина. Москва. [Averboukh, Konstantin. 2006. Obszczaja teorija termina. Moskva.]

Drozd, Dublčins'кı i dr. 1997. = ДРозд, ОлЕнА; Дубгчинський, ВолодимиР Володимирович; Д’яков, Андрій и др. 1997. Словник-посібник економічних термінів (російсько-украӥнсько-англійський). Ред. Кияк, Тарас. Вид. Дім “КМ Аcademia”. Київ. [Drozd, Olena; Dubičins'kis, Volodimir Volodimirovič; D’Jakov, Andrij i dr. 1997. Slovnik-posibnik ekonomičnih terminiv (rosijs'ko-ukraïns'ko-anglijs'kij). Red. Kijak, Taras. Vid. Dim "KM Academia". Kiïv.]

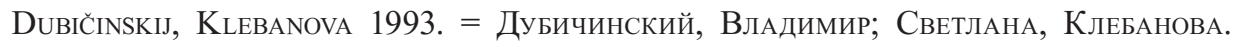
1993. Краткий словарь театральной лексики (русско-англо-фраиузско-испан- 
ский). Харьков. [Dubičinskij, Vladimir; Svetlana, Klebanova. 1993. Kratkij slovar' teatral'noj leksiki (russko-anglo-fracuzsko-ispanskij). Har'kov.]

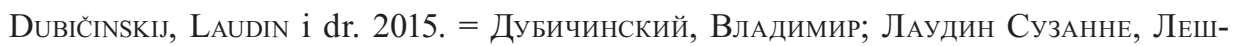
кович ЙоАнна. 2015. Краткий учебный словарь экономических терминов: руссконемецко-польский. Підручник НТУ “ХПI”. Харьков. [DubičinskiJ, VladimiR; Laudin SuZANne, LeŠKOVIČ JOANNA. 2015. Kratkij učebnyj slovar' èkonomičeskih terminov: russko-nemecko-pol'skij. Pidručnik NTU “HPI”. Har'kov.]

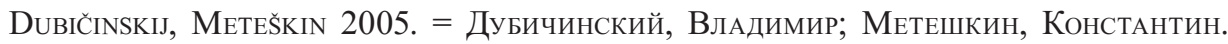
2005. Место и роль современной лексикографии в методологии науки. Прикладная лингвистика. Проблемы построения лингвистического обеспечения образовательных систем высшей школы. Изд-во МСУ. Харьков. 26-32. [DuBičınSKiJ, Vladimir; Meteškin, Konstantin. 2005. Mesto i rol' sovremennoj leksikografii v metodologii nauki. Prikladnaja lingvistika. Problemy postroenija lingvističeskogo obespečenija obrazovatel'nyh sistem vysšej školy. Izd-vo MSU. Har'kov. 26-32.]

DubičInskis, Romanov i dr. 1996. = Дуьичинский, ВлАдимиР; Романов, Юрий; ДАнИЛЕВИч, СЕРГЕй и др. 1996. Русско-английский словарь математических терминов. СПбГТУ. Санкт-Петербург. [Dubičinskij, Vladimir; Romanov, Jurij; Danilevič, Sergej i dr. 1996. Russko-anglijskij slovar' matematičeskih terminov. SPbGTU. SanktPeterburg.]

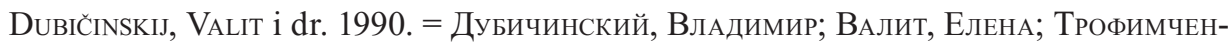
ко, Юрий. 1990. Учебный словарь сочетаемости терминов сельскохозяйственной техники. Ред. Морковкин, Валерий. Русский язык. Москва. [DubičInSKIJ, VladimiR; Valit, Elena; TrofimčEnko, Juris. 1990. Učebnyj slovar' sočetaemosti terminov sel'skohozjajstvennoj tehniki. Red. Morkovkin, Valerij. Russkij jazyk. Moskva.]

DubiČINSKiJ, ZuBAREva i dr. 2000. = ДуБИЧИНСКИЙ, ВЛАДИМИР; ЗуБАРеВА, ВеРА; ОЛЕЙНИк СветЛАНА и др. 2000. Словарь-справочник терминов внешнеэкономической деятельности (Русско-англо-китайский). Крок. Харьков. [DubičınskiJ, Vladimir; Zubareva, Vera; Olejnik Svetlana i dr. 2000. Slovar'-spravočnik terminov vnešneèkonomičeskoj dejatel'nosti (Russko-anglo-kitajskij). Krok. Har'kov.]

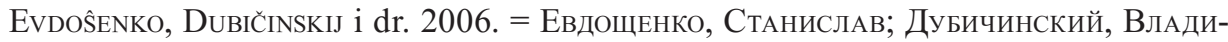
миР; ГАЙВоРонскАЯ, Виктория. 2006. Словарь химических терминов с толкованиями, особенностями употребления и английскими эквивалентами. Феникс. Ростов-на-Дону. [EvdoŝEnko, Stanislav; Dubičinskij, Vladimir; Gajvoronskaja, Viktorija. 2006. Slovar' himičeskih terminov s tolkovanijami, osobennostjami upotreblenija $i$ anglijskimi èkvivalentami. Feniks. Rostov-na-Donu.]

GERD 1986. = ГЕРД, АлЕКСАНДР. 1986. Основы научно-технической лексикографии (Как работать над терминологическим словарём). Изд-во Ленинградского университета. Ленинград. [GERD, Aleksandr. 1986. Osnovy naučno-tehničeskoj 
leksikografii (Kak rabotat' nad terminologičeskim slovarëm). Izd-vo Leningradskogo universiteta. Leningrad.]

GRINËV 2009. = ГРИнЁв, СЕРГЕй. 2009. Введение в терминографию: Как просто и легко составить словарь. Либроком. Москва. [Grinëv, Sergej. 2009. Vvedenie v terminografiju: Kak prosto i legko sostavit' slovar'. Librokom. Moskva.]

GrinËV 2018. = ГРинёв, СЕРГЕй. 2018. Российское терминоведение - итоги и перспективы. Слов'янське термінознавство кіния XX-початку XXI століть. Наук. ред. Іващенко, Вікторія. Видавництво “Жнець”. Київ. 177-203. [Grinëv, Sergej. 2018. Rossijskoe terminovedenie - itogi i perspektivy. Slov'jans'ke terminoznavstvo kincja HH - počatku HHI stolit'. Nauk. red. Ivaŝenko, Viktorija. Vidavnictvo "Žnec'". Kiïv. 177-203.]

LEJČIK 1999. = ЛЕйчик, ВлАдимиР. 1999. Терминоведение. Предмет, методы, структура. Изд-во URSS. Москва [LEJČIK, VLADIMIR. 1999. Obszczaja teorija termina Terminovedenije. Predmet, metody, struktura. Izd-vo URSS. Moskva]

Karpova 2009. = КАРПОВА, ОЛьгА. 2009. Терминологические словари языка писателей: новые тенденции в терминографии. Современные тенденции в лексикологии, терминоведении и теории LSP. Изд-во МГОУ. Москва. 148-153. [KARPOVA, OL'GA. 2009. Terminologičeskie slovari jazyka pisatelej: novye tendencii v terminografii. Sovremennye tendencii $v$ leksikologii, terminovedenii $i$ teorii LSP. Izd-vo MGOU. Moskva. 148-153.]

Komarova 1995. = Комарова, Зоя. 1995. Методология и методика терминографической семантизации. Vocabulum et vocabularium. Ред. Дубичинский, Владимир. Харьков. 43-48. [Komarova, Zoja. 1995. Metodologija i metodika terminografičeskoj semantizacii. Vocabulum et vocabularium. Red. Vladimir, Dubičinskij. Har'kov. 43-48.] LEJČIK 1975. = ЛЕйчик, ВлАдимиР. 1975. Лексикографическая терминологическая деятельность. Терминология библиотечного дела. Москва. 6-15. [LEJčIK, VLADIMIR. 1975. Leksikografičeskaja terminologičeskaja dejatel'nost'. Terminologija bibliotečnogo dela. Moskva. 6-15.]

MARČUK 2007. = МАрчук, Юрий. 2007. Компьютерная лингвистика. АСТ: Восток - Запад. Москва. [MARČUK, JURIJ. 2007. Komp'juternaja lingvistika. AST: Vostok Zapad. Moskva.]

MARČUK 2018. = МАрчук, Юрий. 2018. Многоязычная терминография и терминологическое переводоведение в России конца XX - начала XXI веков. Слов'янське термінознавство кіния XX-початку XXI століть. Наук. ред. Іващенко, Вікторія. Видавництво “Жнець”. Київ. 375-399. [MARс̌UK, JURIJ. 2018. Mnogojazyčnaja terminografija i terminologičeskoe perevodovedenie v Rossii konca HH - načala HHI vekov. Slov'jans'ke terminoznavstvo kincja HH - počatku HHI stolit'. Nauk. red. Ivaŝenko, Viktorija. Vidavnictvo “Žnec". Kiïv. 375-399.] 
Morkovkin 1998. = Морковкин, ВАлЕРий. 1988. О лексикографическом обеспечении профессионально ориентированного обучения русскому языку нерусских студентов. Теория и практика научно-технической лексикографии. Русский язык. Москва. 180-185. [Morkovkin, VALERIJ. 1988. O leksikografičeskom obespečenii professional'no orientirovannogo obučenija russkomu jazyku nerusskih studentov. Teorija i praktika naučno-tehničeskoj leksikografii. Russkij jazyk. Moskva. 180-185.]

OžEgOv 1974. = ОЖегов, СЕРГЕй. 1974. Лексикология. Лексикография. Культура речи. Высшая школа. Москва. [OžEgov, SERgej. 1974. Leksikologija. Leksikografija. Kul'tura reči. Vysšaja škola. Moskva.]

SUPERANSKAJA 2005. = СУПЕРАНСКАЯ, АЛЕКСАНДРА; ПОДОЛЬСКАЯ, НАТАЛЬЯ; ВАСИЛЬЕВА, НАТАЛЬя. 2005. Общая терминология: Терминологическая деятельность. УРСС Эдиториал. Москва. [Superanskaja, Aleksandra; Podol'skaja, Natal'Ja; Vasil'Eva, NATAĹJA. 2005. Obŝjaja terminologija: Terminologičeskaja dejatel'nost'. URSS Èditorial. Moskva.]

TAtARINOv 2006. = Татаринов, Виктор. 2006. Общее терминоведение. Энциклопедический словарь. Московский Лицей. Москва. [TAtARinov, VikTOR. 2006. Obŝee terminovedenie. Ènciklopedičeskij slovar'. Moskovskij Licej. Moskva.]

\section{Vladimir Dubičinskij}

\section{Some Current Issues of Terminography}

\section{Abstract}

In the paper, a variety of problems is outlined, which are nowadays solved by terminography - a synthetical science about the theory and practice of terminological dictionary' creation. The following issues are addressed: most important problems in the modern terminography theory; main types, stages, and requirements of terminological dictionary compilation; alphabet, alphabet-nesting, and ideographical principles of dictionaries creation; standardization of terminology as a terminographic activity; didactical terminography; computerization of terminography, etc. 


\section{Neki suvremeni problemi terminografije}

\section{Sažetak}

U radu se navodi niz problema kojima se danas bavi terminografija - sintetička znanost o teoriji i praksi izrade terminoloških rječnika. Govori se o ovim pitanjima: najčešći problemi moderne terminografske teorije, osnovni tipovi, faze i zahtjevi koji se odnose na izradu terminoloških rječnika, abecediranje, abecedno smještanje i ideografsko načelo stvaranja rječnika, normiranje nazivlja kao terminografska djelatnost, didaktička terminografija, uporaba računala u terminografiji itd.

Ключевые слова: терминография, терминологический словарь, стандарты на термины, учебная терминография, компьютеризация терминологических словарей

Keywords: terminography, terminological dictionary, standards for terms, didactical terminography, computerization of terminological dictionaries

Ključne riječi: terminografija, terminološki rječnik, normiranje naziva, didaktička terminografija, uporaba računala u terminografiji 